\title{
I.UMIBUNG
}

\section{PENGARUH KONSENTRASI PACLOBUTRAZOL TERHADAP PERTUMBUHAN BUNGA MATAHARI (Helianthus annuus L.)}

\author{
Isna Tustiyani $^{1 *}$, Triyani Nurhayati ${ }^{2}$, Jenal Mutakin $^{1}$ \\ ${ }^{1}$ Staf Pengajar Program Studi Agroteknologi Fakultas Pertanian Universitas Garut \\ ${ }^{2}$ Alumni Program Studi Agroteknologi Fakultas Pertanian Universitas Garut \\ *) e-mail : isnatustiyani@gmail.com
}

$\begin{array}{ll}\text { Diterima } & : 20 \text { Mei } 2020 \\ \text { Disetujui } & : 25 \text { Agustus } 2020 \\ \text { Diterbitkan } & : 31 \text { Agustus 2020 }\end{array}$

\begin{abstract}
ABSTRAK
Bunga matahari (Helianthus annuus L.) merupakan salah satu tanaman hias. Salah satu cara mengoptimalkan pertumbuhan tanaman hias adalah dengan penggunaan zat penghambat pertumbuhan (retardan) paclobutrazol. Benih bunga matahari yang digunakan yaitu benih IPB $\mathrm{BM}_{1}$. Tujuan penelitian ini untuk mengetahui pengaruh pemberian paclobutrazol pada pertumbuhan tanaman bunga matahari serta mengetahui konsentrasi paclobutrazol terbaik pada pertumbuhan tanaman bunga matahari. Percobaan ini dilakukan di lahan sawah Kp. Sindang Sari Rt 001/Rw 006 dari bulan Maret sampai Juli 2019. Percobaan ini menggunakan Rancangan Acak Kelompok Pola Tunggal, dengan perlakuan paclobutrazol berbagai konsentrasi $0,1 \mathrm{ml} / \mathrm{L}, 2 \mathrm{ml} / \mathrm{L}, 3 \mathrm{ml} / \mathrm{L}, 4 \mathrm{ml} /, 5 \mathrm{ml} / \mathrm{L}$. Variabel pengamatan yang diamati yaitu : tinggi tanaman, jumlah daun, luas daun, jumlah bunga, diameter bunga, dan umur muncul bunga. Hasil penelitian menunjukan bahwa paclobutrazol berpengaruh nyata terhadap tinggi tanaman dan luas daun.
\end{abstract}

\section{Kata Kunci : Paclobutrazol, Pertumbuhan, Konsentrasi, Bunga Matahari (Helianthus annuus L.)}

\begin{abstract}
Sunflower (Helianthus annuus L.) is an decorative plants. One of the ways is to growth optimize with use retardants paclobutrazol. Sunflower seeds used IPB BM. The purpose of this study was to determine the effect of paclobutrazol on the growth of sunflower plants and determine the best concentration of paclobutrazol on the growth of sunflower plants. This research was conducted at Kp. Sindang Sari Rt $001 / R w 006$ from March to July 2019. This study uses a Single Randomized Pattern Design, with the treatment of paclobutrazol in various concentrations of $0,1 \mathrm{ml} / \mathrm{L}, 2 \mathrm{ml} / \mathrm{L}, 3 \mathrm{ml} / \mathrm{L}, 4 \mathrm{ml} /, 5 \mathrm{ml} / \mathrm{L}$. Observation variables: plant height, number of leaves, leaf area, number of flowers, diameter of flowers, and age appears interest. The results showed that paclobutrazol had a significantly effect to the plant height, and leaf area.
\end{abstract}

Keywords: Paclobutrazol, Growth, Concentration, Sunflower (Helianthus annuus L.) 


\section{I.UMIBUNC}

\section{PENDAHULUAN}

Bunga matahari adalah salah satu bunga hias yang memiliki perilaku khas, yaitu bunganya selalu menghadap ke arah matahari atau heliotropisme. Bangsa Perancis menyebutnya tournesol atau "Pengelana Matahari" (Herwati et al., 2011). Bunga matahari (Helianthus annuus L.) di Indonesia biasanya dimanfaatkan oleh masyarakat sebagai tanaman pagar untuk menghiasi halaman rumahnya sedangkan di luar negeri seperti di negara Eropa dan Amerika memanfaatkannya sebagai bunga potong dan penghasil minyak nabati yang sangat potensial untuk menambah nilai ekonomis.

Menurut Dasoju et al (1998), bunga matahari tidak layak dibudidayakan dalam pot karena tanaman tumbuh terlalu tinggi dan mudah rebah bila sudah berbunga. Salah satu cara agar dapat di tanam di dalam pot adalah dengan mengurangi tinggi tanaman bunga matahari tanpa mengurangi kualitas dari keindahan bunga matahari tersebut (Wirdayanto et al., 2011). Beragamnya jenis tanaman hias membuat orang perlu untuk mengoptimalkan pertumbuhan tanaman hias salah satu caranya adalah dengan penggunaan zat penghambat pertumbuhan (retardan) paclobutrazol.

Retardan merupakan kelompok zat pengatur tumbuh yang dapat menghambat pemanjangan batang melalui penghambatan biosintesis giberelin (Wattimena, 1988). Penggunaan retardan dapat menjadi solusi untuk mengatasi potensi kerebahan pada tanaman pot bunga matahari. Zat pengatur tumbuh diketahui dapat mengendalikan banyak proses di dalam tanaman baik itu mempercepat ataupun memperlambat proses pertumbuhan bagian-bagian tanaman tertentu, salah satu kegunaan ZPT adalah sebagai zat penghambat pertumbuhan. Zat penghambat pertumbuhan dapat digunakan sebagai salah satu alternatif untuk meningkatkan produksi bunga, zat penghambat tumbuh yang biasa digunakan adalah paclobutrazol. Paclobutrazol merupakan jenis retardan yang banyak digunakan untuk mempercepat pembungaan pada tanaman (Tustiyani et al., 2018). Tujuan penelitian ini untuk mengetahui pengaruh pemberian paclobutrazol pada pertumbuhan tanaman bunga matahari serta mengetahui konsentrasi paclobutrazol terbaik pada pertumbuhan tanaman bunga matahari.

\section{METODE PENELITIAN}

Percobaan dilaksanakan di Kampung Sindang Sari RT/001 RW/006 Desa Ciburial Kecamatan Leles Kabupaten Garut pada Maret sampai Juli 2019. Ordo tanah termasuk Inseptisols dengan $\mathrm{pH}$ tanah 6.62. Ketinggian 700 mdpl. 


\section{I.UMIBUNG}

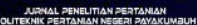

Bahan-bahan yang digunakan pada penelitian ini adalah benih bunga matahari IPB $\mathrm{BM}_{1}$, paclobutrazol, pupuk kandang, pupuk $\mathrm{KCl}, \mathrm{SP}-36$, dan pupuk urea. Alat-alat yang digunakan pada penelitian ini adalah tray kecil untuk persemaian benih, meteran, mistar, timbangan analitik, oven, wadah, kamera (alat dokumentasi), papan perlakuan, hand counter, papan plot, alat tulis.

Penelitian dilakukan dengan menggunakan Rancangan Acak Kelompok (RAK) yang terdiri dari enam perlakuan dengan empat ulangan yaitu, $\mathrm{P}_{0}=$ Kontrol, $\mathrm{P}_{1}=1$ $\mathrm{ml} / \mathrm{L}, \mathrm{P}_{2}=2 \mathrm{ml} / \mathrm{L}, \mathrm{P}_{3}=3 \mathrm{ml} / \mathrm{L}, \mathrm{P}_{4}=4 \mathrm{ml} / \mathrm{L}, \mathrm{P}_{5}=5 \mathrm{ml} / \mathrm{L}$. Terdapat enam perlakuan yang diulang sebanyak empat kali sehingga diperoleh 24 satuan percobaan. Setiap satuan percobaan terdiri dari 10 tanaman, dan 5 tanaman dijadikan sebagai tanaman sampel sehingga secara keseluruhan terdapat 240 tanaman. Masing-masing tanaman dilakukan penyiraman larutan paclobutrazol dengan volume $100 \mathrm{ml} / \operatorname{tanaman}$ sebanyak 1 kali penyiraman pada umur 4 MST.

\section{HASIL DAN PEMBAHASAN}

\section{Tinggi Tanaman}

Hasil analisis statistik tinggi tanaman bunga matahari menunjukan bahwa penambahan paclobutrazol tidak memberikan pengaruh yang nyata pada periode pengamatan 2 dan 4 MST, namun memberikan pengaruh pada periode pengamatan 6 dan 8 MST. Semua tanaman bunga matahari yang mendapat perlakuan mengalami kenaikan, meskipun dengan kecepatan pertambahan tinggi yang berbeda.

Tabel 1. Rerata Pertumbuhan Tinggi Tanaman Bunga Matahari yang Mendapat Perlakuan Paclobutrazol.

\begin{tabular}{ccccc}
\hline \multirow{2}{*}{ Perlakuan } & \multicolumn{4}{c}{ Tinggi Tanaman (cm) } \\
& $2 \mathrm{MST}$ & $4 \mathrm{MST}$ & $6 \mathrm{MST}$ & $8 \mathrm{MST}$ \\
\hline 0 ml Paclobutrazol/L & $19.95 \mathrm{a}$ & $44.52 \mathrm{a}$ & $87.82 \mathrm{ab}$ & $141.05 \mathrm{ab}$ \\
$1 \mathrm{ml} \mathrm{Paclobutrazol/L}$ & $20.57 \mathrm{a}$ & $50.57 \mathrm{a}$ & $93.72 \mathrm{~b}$ & $154.55 \mathrm{~b}$ \\
$2 \mathrm{ml}$ Paclobutrazol/L & $19.95 \mathrm{a}$ & $43.02 \mathrm{a}$ & $75.77 \mathrm{a}$ & $138.02 \mathrm{ab}$ \\
$3 \mathrm{ml} \mathrm{Paclobutrazol} / \mathrm{L}$ & $20.47 \mathrm{a}$ & $44.70 \mathrm{a}$ & $82.50 \mathrm{ab}$ & $129.85 \mathrm{ab}$ \\
$4 \mathrm{ml}$ Paclobutrazol/L & $17.32 \mathrm{a}$ & $41.55 \mathrm{a}$ & $69.80 \mathrm{a}$ & $125.82 \mathrm{a}$ \\
$5 \mathrm{ml}$ Paclobutrazol/L & $20.10 \mathrm{a}$ & $48.57 \mathrm{a}$ & $80.05 \mathrm{ab}$ & $141.17 \mathrm{ab}$ \\
\hline
\end{tabular}

Keterangan : Angka rata-rata yang diikuti huruf yang sama pada setiap kolom, tidak berbeda nyata menurut Uji Jarak Berganda Duncan pada taraf 5\%.

Berdasarkan Tabel 1 di atas perlakuan paclobutrazol pada periode pengamatan 6 dan 8 MST memberikan pengaruh yang nyata pada peubah tinggi tanaman. Hasil 


\section{I.UMIBUNG}

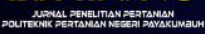

penelitian tertinggi yaitu pada taraf perlakuan $1 \mathrm{ml} / \mathrm{L}$ yaitu : 92,72 $\mathrm{cm}$ dan $154,55 \mathrm{~cm}$. Hasil penelitian tersebut dapat disimpulkan bahwa taraf perlakuan terbaik yaitu $1 \mathrm{ml} / \mathrm{L}$ untuk menghambat tinggi tanaman bunga matahari dengan perlakuan paclobutrazol. Menurut Salisbury dan Ross (1995) paclobutrazol merupakan salah satu zat penghambat tumbuh yang bekerja dengan menghambat sintesis giberelin sehingga dapat menghambat pemanjangan batang dan menyebabkan pengkerdilan. Santiasrini (2009) mengemukakan bahwa pemberian paclobutrazol dengan konsentrasi yang semakin tinggi akan menyebabkan tinggi tanaman semakin rendah.

Hasil pengamatan menunjukan bahwa aplikasi paclobutrazol dengan konsentrasi 4 $\mathrm{ml} / \mathrm{L}$ mampu memberikan penghambatan pertumbuhan tinggi tanaman bunga matahari dengan tinggi terendah 69.80 dan 125.82 selama 2 minggu dan 4 minggu setelah aplikasi perlakuan paclobutrazol (6 dan 8 MST). Perlakuan paclobutrazol dengan konsentrasi 4 $\mathrm{ml} / \mathrm{L}$ mengalami pertambahan tinggi terendah dibandingkan dengan perlakuan lain, hal ini membuktikan bahwa perakuan dengan konsentrasi $4 \mathrm{ml} / \mathrm{L}$ cenderung dapat menghambat pertumbuhan vegetatif pada umur 6 MST meskipun dalam perhitungan analisis statistik tidak berbeda nyata. Penghambatan pertumbuhan tinggi tanaman tersebut merupakan pengaruh yang ditimbulkan dari paclobutrazol dalam menghambat produksi giberellin (Rubiyanti dan Rochayat, 2015).

\section{Jumlah Daun}

Hasil analisis statistik jumlah daun bunga matahari menunjukan bahwa penambahan paclobutrazol tidak memberikan pengaruh yang nyata pada semua periode pengamatan umur 2 sampai 8 MST (Tabel 2).

Tabel 2. Rerata Jumlah Daun Bunga Matahari yang Mendapat Perlakuan Paclobutrazol.

\begin{tabular}{ccccc}
\hline \multicolumn{1}{c}{ Perlakuan } & \multicolumn{3}{c}{ Jumlah Daun (Helai) } \\
& $2 \mathrm{MST}$ & $4 \mathrm{MST}$ & $6 \mathrm{MST}$ & $8 \mathrm{MST}$ \\
\hline $0 \mathrm{ml}$ Paclobutrazol//L & $7.85 \mathrm{a}$ & $14.85 \mathrm{a}$ & $20.75 \mathrm{a}$ & $23.75 \mathrm{a}$ \\
$1 \mathrm{ml} \mathrm{Paclobutrazol//L}$ & $9.45 \mathrm{a}$ & $16.50 \mathrm{a}$ & $21.75 \mathrm{a}$ & $25.20 \mathrm{a}$ \\
$2 \mathrm{ml} \mathrm{Paclobutrazol} / \mathrm{L}$ & $7.60 \mathrm{a}$ & $14.40 \mathrm{a}$ & $20.65 \mathrm{a}$ & $23.90 \mathrm{a}$ \\
$3 \mathrm{ml} \mathrm{Paclobutrazol//L}$ & $8.10 \mathrm{a}$ & $15.30 \mathrm{a}$ & $20.85 \mathrm{a}$ & $23.05 \mathrm{a}$ \\
$4 \mathrm{ml} \mathrm{Paclobutrazol//L}$ & $7.75 \mathrm{a}$ & $14.25 \mathrm{a}$ & $19.40 \mathrm{a}$ & $24.05 \mathrm{a}$ \\
$5 \mathrm{ml} \mathrm{Paclobutrazol//L}$ & $8.70 \mathrm{a}$ & $15.85 \mathrm{a}$ & $20.55 \mathrm{a}$ & $24.35 \mathrm{a}$ \\
\hline
\end{tabular}

Keterangan : Angka rata-rata yang diikuti huruf yang sama pada setiap kolom, tidak berbeda nyata menurut Uji Jarak Berganda Duncan pada taraf 5\%. 


\section{I.UMIBUNG}

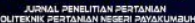

Hasil penelitian yang menunjukan jumlah daun tidak berbeda nyata terjadi karena disebabkan oleh zat penghambat tumbuh paclobutrazol menghambat kerja giberelin yang berhubungan dengan pemanjangan batang sehingga tidak mempengaruhi jumlah daun. Hal ini sesuai dengan pernyataan Marshel (2015) bahwa penghambatan pertumbuhan yang diakibatkan oleh aplikasi paclobutrazol muncul karena komponen kimia yang terkandung dalam paclobutrazol menghalangi tiga tahapan untuk produksi giberelin pada jalur terpenoid dengan cara menghambat enzim yang mengkatalisasi proses reaksi metabolis. Salah satu fungsi utama dari giberelin adalah untuk menstimulasi perpanjangan sel ketika produksi giberelin dihambat, pembelahan sel tetap terjadi namun sel-sel baru tidak mengalami pemanjangan. Menurut Widaryanto (2011) tidak terjadinya pengaruh nyata pada parameter jumlah daun disebabkan karena faktor genetik dari tanaman bunga matahari itu sendiri.

\section{Luas Daun (cm)}

Berdasarkan Tabel 3 menunjukan bahwa perlakuan paclobutrazol memberikan pengaruh terhadap luas daun bunga matahari. Salah satu yang mempengaruhi luas daun dalam penelitian ini adalah jumlah ketersediaan air yang diterima oleh tanaman, semakin optimum air yang diterima pada saat penyiraman oleh tanaman maka semakin maksimal pertumbuhan tanaman tercapai. Semakin tinggi luas daun, berarti fotosintat yang dihasilkan semakin banyak dan pada akhirnya akan berakibat pada biomas tanaman yang dihasilkan akan semakin tinggi.

Tabel 3. Rerata Luas Daun Bunga Matahari yang Mendapat Perlakuan Paclobutrazol.

\begin{tabular}{cc}
\hline Perlakuan & Luas Daun $(\mathrm{cm})$ \\
\hline $0 \mathrm{ml}$ Paclobutrazol//L & $3036,3 \mathrm{ab}$ \\
$1 \mathrm{ml}$ Paclobutrazol//L & $2961,3 \mathrm{a}$ \\
$2 \mathrm{ml}$ Paclobutrazol//L & $2489,3 \mathrm{a}$ \\
$3 \mathrm{ml}$ Paclobutrazol//L & $3419,5 \mathrm{ab}$ \\
$4 \mathrm{ml}$ Paclobutrazol//L & $4815,5 \mathrm{~b}$ \\
$5 \mathrm{ml}$ Paclobutrazol//L & $4380,0 \mathrm{~b}$ \\
\hline
\end{tabular}

Keterangan : Angka rata-rata yang diikuti huruf yang sama pada setiap kolom, tidak berbeda nyata menurut Uji Jarak Berganda Duncan pada taraf 5\%.

Pada dasarnya paclobutrazol merupakan retardan yang bersifat menurunkan aktivitas metabolisma jaringan dan dapat menghambat proses pertumbuhan vegetatif (Purnomo dan Prahandini (1991) sehingga pada konsentrasi tertentu akan terlihat 


\section{I.UMIBUNG}

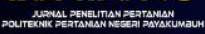

perbedaan pada lama masa aktif suatu organ vegetatif, misalkan daun, sehingga daun dapat lebih lama waktunya sebelum layu.

\section{Jumlah dan diameter Bunga}

Hasil analisis statistik jumlah dan diameter bunga matahari menunjukan bahwa penambahan paclobutrazol tidak memberikan pengaruh yang nyata pada semua taraf perlakuan terhadap parameter jumlah, diameter dan umur muncul bunga (Tabel 4).

Tabel 4. Jumlah, Diameter dan Umur Muncul Bunga Matahari yang Mendapat Perlakuan Paclobutrazol.

\begin{tabular}{cccc}
\hline Perlakuan & Jumlah Bunga & Diameter bunga (cm) & $\begin{array}{c}\text { Umur Muncul } \\
\text { Berbunga (MST) }\end{array}$ \\
\hline $0 \mathrm{ml}$ Paclobutrazol//L & $5,8 \mathrm{a}$ & $22,25 \mathrm{a}$ & $9,90 \mathrm{a}$ \\
$1 \mathrm{ml} \mathrm{Paclobutrazol//L}$ & $3,9 \mathrm{a}$ & $23,02 \mathrm{a}$ & $9,55 \mathrm{a}$ \\
$2 \mathrm{ml} \mathrm{Paclobutrazol//L}$ & $4,1 \mathrm{a}$ & $22,25 \mathrm{a}$ & $10,05 \mathrm{a}$ \\
$3 \mathrm{ml} \mathrm{Paclobutrazol//L}$ & $4,7 \mathrm{a}$ & $21,27 \mathrm{a}$ & $9,80 \mathrm{a}$ \\
$4 \mathrm{ml} \mathrm{Paclobutrazol//L}$ & $4,9 \mathrm{a}$ & $21,20 \mathrm{a}$ & $10,00 \mathrm{a}$ \\
$5 \mathrm{ml} \mathrm{Paclobutrazol//L}$ & $4,9 \mathrm{a}$ & $22,10 \mathrm{a}$ & $10,02 \mathrm{a}$ \\
\hline
\end{tabular}

Keterangan : Angka rata-rata yang diikuti huruf yang sama pada setiap kolom, tidak berbeda nyata menurut Uji Jarak Berganda Duncan pada taraf 5\%.

Berdasarkan Tabel 4 di atas menunjukkan bahwa perlakuan berbagai konsentrasi paclobutrazol tidak berbeda nyata pada jumlah dan diameter bunga. Karakter jumlah bunga lebih banyak dipengaruhi oleh genetik tanaman. Mansuroglu et al., (2009) mengatakan bahwa respon paclobutrazol terhadap diameter bunga pada tanaman cukup beragam bergantung pada jenis dan kultivar tanaman yang diberi paclobutrazol. Andayani (2004) juga menyatakan bahwa pemberian paclobutrazol 500 ppm dan 1000 ppm tidak berpengaruh secara nyata terhadap diameter bunga melati.

Berdasarkan Tabel 4 menunjukan bahwa perlakuan berbagai konsentrasi paclobutrazol tidak memberi perbedaan pada parameter umur muncul bunga. Nugroho (2010) menyatakan pengaruh retardan terhadap pembungaan merupakan pengaruh sekunder, sedangkan pengaruh primernya adalah penekanan pertumbuhan vegetatif. Menurut Wattimena (1990), dari beberapa teori pemberian zat pengatur tumbuh untuk mempengaruhi pembungaan maka ada tiga hal yang berlaku umum, yaitu : (1) genotip tanaman menentukan pola pembungaan, (2) tanaman harus mencapai stadia matang untuk berbunga baru respon terhadap perlakuan pembungaan dan (3) ada beberapa zat pengatur tumbuh yang mengatur pembungaan itu. 


\section{I.UMIBUNG}

\section{KESIMPULAN}

Penambahan paclobutrazol pada tanaman bunga matahari dengan berbagai konsentrasi yang berbeda berpengaruh secara nyata pada tinggi tanaman dan luas daun. Penambahan paclobutrazol pada bunga matahari memberikan konsentrasi terbaik yaitu 4 $\mathrm{ml} / \mathrm{L}$.

\section{REFERENSI}

Andayani W. 2004. Pengaruh Paclobutrazol dan Pupuk Organik terhadap Pembungaan Melati (Jasminum sambac var. Menur Mekar Sari). Skripsi. Jurusan Budidaya Pertanian, Fakultas Pertanian. Institut Pertanian Bogor. 35 hal.

Dasoju, S., M., Evans, R dan Whipker, B. 1998. Paclobutrazol Drenche Control Growth of Potted Sunflowers.

Herwati, A., Purwati, R. D., dan Anggraeni, T. D. A. 2011. Penampilan Karakter Kualitatif Pada Plasma Nutfah Tanaman Bunga-Matahari. Prosiding. Seminar Nasional Inovasi Perkebunan. Balai Penelitian Tanaman Tembakau dan Serat. Malang.

Karaguzel, O., I. Baktir., S. Cakmakci. dan V. Ortacesme. 2004. Growth and flowering responses of Lupinus varius L. to paclobutrazol. Journal Horticulture Science, volume 39(7): 1659-1663

Mansuroglu, S., O. Karaguzel, V. Ortacesme and M.S. Sayan. 2009. Effect of Paclobutrazol on Flowering Leaf and Colour of Consolida orientalis. Pak. J. Bot., 41(5): 2323-2332

Nugroho, P.T. 2012. Pengaruh Paclobutrazol Dan Komposisi Larutan Pulsing Terhadap Kualitas Pasca Panen Bunga Matahari (Helianthus annuus L.) Sebagai Bunga Potong. Departemen Agronomi Dan Hortikultura Fakultas Pertanian Institut Pertanian Bogor.

Purnomo, Prahandini. 1991. Pengaruh saat aklimatisasi dan konsentrasi paclobutrazol selama dua musim panen apel (Malus syvestris Mill). Jurnal Hortikultura. 1(2): 58-68.

Rubiyanti, N. Rochayat, Y. 2015. Pengaruh konsentrasi paklobutrazol dan waktu aplikasi terhadap mawar batik (Rosa hybrida L.). Jurnal Kultivasi Vol. 14 (1): 59-64.

Salisbury, F.B. dan C.W. Ross. 1995. Fisiologi Tumbuhan 3. Jilid 3. Diterjemahkan oleh Diah R.Lukman dan Sumaryono dengan Penyunting Sofia Niksolihin.ITB. Bandung. 343 hal. 


\section{I.UMIBUNG}

Santiasrini, R. 2009. Pengaruh paklobutrazol terhadap pertumbuhan dan pembungaan gloksinia (Sinningia speciosa Pink). (Skripsi). Program Studi Hortikultura. Fakultas Petanian. Institut Pertanian Bogor. Bogor. 61 hal.

Tustiyani, I., Yasinta A., Maesyaroh, SS. 2018. Effect of Paclobutrazol Concentration and Wire Winding on Off-Season Flowering Induction in Orange Plants. Proceeding The International Seminar on Tropical Horticulture: Horticulture for The Quality of Life. Bogor, December 10th, 2018

Untung, K. 2001. Pengantar Pengelolaan Hama Terpadu UGM. Press. Yogyakarta

Wattimena, G.A. 1988. Zat Pengatur Tumbuh Tanaman. Pusat Antar Universitas (PAU) Bioteknologi IPB. Bogor.

Widaryanto,E., Baskara, M dan Suryanto,A. 2011. Aplikasi Paclobutrazol Pada Tanaman Bunga Matahari (Hellianthus annuus L. cv. Teddy Bear) Sebagai Upaya Menciptakan Tanaman Hias Pot. Makalah. Fakultas Pertanian Universitas Brawijaya. 